\title{
Empowering Patients during Hospitalization: Perspectives on Inpatient Portal Use
}

\author{
Ann Scheck McAlearney 1,2,3,4 Naleef Fareed $^{2,3} \quad$ Alice Gaughan $^{2} \quad$ Sarah R. MacEwan ${ }^{2}$ \\ Jaclyn Volney ${ }^{2}$ Cynthia J. Sieck ${ }^{1,2}$
}

${ }^{1}$ Department of Family Medicine, College of Medicine, The Ohio State
University, Columbus, Ohio, United States
${ }^{2}$ CATALYST, Center for the Advancement of Team Science, Analytics,
and Systems Thinking, College of Medicine, The Ohio State
University, Columbus, Ohio, United States
${ }^{3}$ Department of Biomedical Informatics, College of Medicine,
The Ohio State University, Columbus, Ohio, United States
${ }^{4}$ Division of Health Services Management and Policy, College of Public
Health, The Ohio State University, Columbus, Ohio, United States

Address for correspondence Ann Scheck McAlearney, ScD, MS, CATALYST, Center for the Advancement of Team Science, Analytics, and Systems Thinking in Health Services and Implementation Science Research, College of Medicine, Ohio State University, 460 Medical Center Drive, Suite 530, Columbus, OH 43210, United States (e-mail: Ann.McAlearney@osumc.edu).

Appl Clin Inform 2019;10:103-112.

\section{Abstract}

Keywords

- patient portals

- hospitalization

- medical informatics

- engagement

- empowerment
Background Patients have demonstrated an eagerness to use portals to access their health information and connect with care providers. While outpatient portals have been extensively studied, there is a recognized need for research that examines inpatient portals.

Objective We conducted this study to improve our understanding about the role of a portal in the context of inpatient care. Our study focused on a large sample of the general adult inpatient population and obtained perspectives from both patients and care team members about inpatient portal use.

Methods We interviewed patients $(n=120)$ who used an inpatient portal during their hospitalization at 15 days or 6 months after discharge to learn about their portal use. We also interviewed care team members $(n=331) 4$ weeks, 6 months, and 12 months after inpatient portal implementation to collect information about their ongoing perspectives about patients' use of the portal.

Results The perspectives of patients and care team members generally converged on their views of the inpatient portal. Three features-(1) ordering meals, (2) looking up health information, and (3) viewing the care team-were most commonly used; the secure messaging feature was less commonly used and of some concern to care team members. The inpatient portal benefited patients in four main ways: (1) promoted independence, (2) reduced anxiety, (3) informed families, and (4) increased empowerment.

Conclusion Inpatient portals are recognized as a tool that can enhance the delivery of patient-centered care. In addition to empowering patients by increasing their sense of control, inpatient portals can support family members and caregivers throughout the hospital stay. Given the consistency of perspectives about portal use across patients and care team members, our findings suggest that inpatient portals may facilitate shifts in organizational culture that increase the patient centeredness of care and improve patient experience in the hospital context. received

June 30, 2018

accepted after revision

December 10, 2018 (c) 2019 Georg Thieme Verlag KG Stuttgart · New York
DOI https://doi.org/

$10.1055 / \mathrm{s}-0039-1677722$ ISSN 1869-0327. 


\section{Background and Significance}

The patient experience during hospitalization is often stressful as each patient faces the uncertainty of changes in their health. The hospital setting, however, can serve as a trigger for patient engagement, whereby patients are integrated as active participants in their ongoing health care. ${ }^{1-3}$ As such, aspects of patient experience in the hospital setting have been shown to positively influence health outcomes; patients reporting positive patient-provider communication $^{4}$ or optimal shared decision making ${ }^{5}$ achieve better health outcomes including self-reported physical and mental health, adherence to quality of care measures (e.g., statin and aspirin use), and decreased emergency room visits, as compared with those reporting poor patient experience. Identifying the factors that influence the patient experience is important for implementing strategies that support patient engagement and ultimately achieve better health outcomes.

With the goal of improving patient engagement, the movement toward patient-centered care seeks to address factors such as care coordination, communication, and involvement of family and friends that influence the patient experience. ${ }^{6}$ Hospitals that have achieved high performance in patient-centered care have identified strategies that have improved patient experience, such as a culture of commitment to serving patients and their families; an effort to enhance patient-provider interactions through responsiveness, proactive communication, and caring behaviors; and an effort to educate care providers on the importance of patient experiences. ${ }^{7}$ In this context, patient portals have emerged as a technology that helps hospitals provide patient-centered care by increasing accessibility to health information and supporting patient-provider communication. ${ }^{8,9}$

Recent studies provide evidence that patients are eager to adopt patient portals to access their personal health information (PHI) as well as maintain relationships with their providers. ${ }^{10}$ As a reflection of this interest, the use of patient portals to manage PHI and communicate with care providers has continually increased over time. ${ }^{11,12}$ While predominantly implemented in the outpatient setting, patient portals have nonetheless been shown to improve patient engagement with their health care and providers. ${ }^{8}$

Patient portals tailored for the inpatient experience are gaining interest as a means to improve patient-centered care during hospitalization. Studies have noted that patients find access to their PHI helpful during hospitalization, and desire additional information regarding their health care in a format that can help them remember details that may otherwise only be provided verbally from a care provider. ${ }^{13,14}$ Inpatient portals, like outpatient portals, provide access to medical information and a patient-provider communication platform. Currently, studies of inpatient portals lag behind those of outpatient portals, and there is a recognized need for research that examines the impact of inpatient portals on patient-centered care and health outcomes. $^{15}$

\section{Objective}

We conducted this study to improve our understanding about the role of a portal in the context of inpatient care. We were interested in learning about the use of inpatient portal features and the implications of portal use from the perspectives of both patients who had used the portal while in the hospital and care team members involved in the care of hospitalized patients.

\section{Methods}

\section{Study Design}

We conducted an extensive qualitative study, including interviews with both patients and care team members, as part of a system-wide implementation of an inpatient portal at a large Midwestern academic medical center (AMC) consisting of six hospitals and 53 outpatient units. This AMC utilizes the Epic Systems Corporation (Verona, Wisconsin, United States) electronic health record (EHR) which includes the outpatient portal, MyChart, and the inpatient portal, MyChart Bedside. Upon admission, nurses conduct an assessment to determine if the patient should be offered an Android tablet equipped with the MyChart Bedside application, based on the following criteria: over age 18, English speaking, nonprisoner, and physically and cognitively capable of managing the technology. Both tablet use and study participation are voluntary. After the patient agrees that they would like access to the tablet during their hospital stay, the care team provisions the tablet, syncs it with the patient's EHR, and instructs the patient to create an account and personal identification number. The tablet is connected to the Internet so that patients can also use it for other purposes such as accessing social media, email, and entertainment.

The MyChart Bedside application consists of eight features listed in $>$ Table 1. Each hospital unit determines their own workflow for provisioning the tablet to patients and documenting patient acceptance of the tablet. The majority of units require a nurse to assess eligibility and interest in tablet use, but the actual provisioning of the tablet to the patient is often the task of the unit's patient care assistant (i. e., a nursing assistant). All care team members were trained in the provisioning process and overall purpose of MyChart Bedside through a variety of means including in-service training, online modules, and peer-to-peer demonstrations; further, "super users" who received additional training were available on most units.

All interviews were conducted between January 2017 and May 2018. The Ohio State University's Institutional Review Board approved this study.

\section{Data Collection}

Patient Interviews: We conducted two phases of telephone interviews with patients randomly selected from all discharged patients who had consented to our study. Phase 1 interviews $(n=60)$ took place 15 days after discharge and phase 2 interviews $(n=60)$ took place 6 months after discharge. We investigated these two time periods to capture 
Table 1 Features of MyChart Bedside inpatient portal

\begin{tabular}{|l|l|l|}
\hline Portal function & $\begin{array}{l}\text { MyChart Bedside } \\
\text { portal feature }\end{array}$ & Example quotation describing patient use \\
\hline Scheduling & Happening soon & $\begin{array}{l}\text { "They can look on there and see what time their medications are due. } \\
\text { They can look to see when their upcoming tests are." }\end{array}$ \\
\hline Health information & My health & $\begin{array}{l}\text { "I've seen a lot love looking up their medications, what's my, } \\
\text { what are my next medications due, and their vitals." }\end{array}$ \\
\hline Health education & To learn & $\begin{array}{l}\text { "I had a guy who finished all his education modules and l'm like would you like } \\
\text { more? He goes, 'No it's okay'. But he completed every single one that was on } \\
\text { there." }\end{array}$ \\
\hline Secure messaging & Messages & $\begin{array}{l}\text { "Somebody like wanted to see a social worker, they just had like a discharge } \\
\text { question about their facility...somebody else like had, they wanted their } \\
\text { nurse to explain something about medication." }\end{array}$ \\
\hline View care team & Taking care of me & $\begin{array}{l}\text { "They get their care team, like us. We show on there our pictures and little bit } \\
\text { of history you know." }\end{array}$ \\
\hline Request a service or item & I would like & $\begin{array}{l}\text { "I see them order food a lot on it, which is nice." } \\
\text { when she came to visit and that kind of thing we have had a couple of those } \\
\text { where if we hadn't of started this we wouldn't have known that was } \\
\text { necessarily an option." }\end{array}$ \\
\hline Make notes & $\begin{array}{l}\text { “I actually had a deaf patient that was unable to speak and it was much easier } \\
\text { for him to type out his messages." }\end{array}$ \\
\hline
\end{tabular}

information that went beyond initial impressions of portal use by the patient, providing immediate impressions from the first phase of interviews, and more lasting impressions 6 months postdischarge. The demographic characteristics of these interviewed patients are presented in -Table 2 , by phase.

We used a semistructured interview guide that asked questions about patients' experiences with the inpatient portal and benefits they perceived from using this new technology. Please see the Supplementary Material (available in the online version) for a copy of the patient interview guides. Interviews lasted approximately 15 minutes each and were audio-recorded and then transcribed verbatim. Interview transcripts were deidentified so that interviewee information was not included.

Care Team Member Interviews: With care team members, we conducted three phases of in-person interviews with nurses, patient care assistants, and unit clinic assistants (i.e., unit administrative assistants) across the 53 hospital units. Phase 1 interviews $(n=105)$ took place within 4 weeks of implementation of the MyChart Bedside application; phase 2 interviews ( $n=112$ ) were conducted 6 months postimplementation; and phase $3(n=114)$ interviews were conducted 12 months postimplementation. We conducted multiple phases of interviews with staff because we were interested in following their perceptions about inpatient portal use over time as they gained greater exposure to the inpatient portal and observed patients' use of the portal tool. Across phases, we completed 331 care team member interviews, as shown in - Table 2.

We used a different semistructured interview guide to conduct care team member interviews and asked questions about both care team members' experiences and perceptions of patients' experiences with the inpatient portal (i.e., based

Table 2 Interviewees, by interview phase

\begin{tabular}{|c|c|c|c|c|c|c|}
\hline \multicolumn{3}{|c|}{ Patient interviewees } & \multicolumn{4}{|c|}{ Care team member interviewees } \\
\hline & $\begin{array}{l}\text { Phase } 1 \\
\text { (15 days } \\
\text { postdischarge) }\end{array}$ & $\begin{array}{l}\text { Phase } 2 \\
\text { ( } 6 \text { months } \\
\text { postdischarge) }\end{array}$ & & $\begin{array}{l}\text { Phase } 1 \\
\text { (within } 4 \text { weeks of } \\
\text { implementation) }\end{array}$ & $\begin{array}{l}\text { Phase } 2 \\
\text { ( } 6 \text { months } \\
\text { postimplementation) }\end{array}$ & $\begin{array}{l}\text { Phase } 3 \\
\text { ( } 12 \text { months } \\
\text { postimplementation) }\end{array}$ \\
\hline $\begin{array}{l}\text { Mean age, } \\
\text { years (SD) }\end{array}$ & $49.4(14.3)$ & $49.4(13.7)$ & Nurses & 74 & 80 & 73 \\
\hline Percent male & 30 & 25 & $\begin{array}{l}\text { Patient care } \\
\text { assistants } \\
\text { and unit } \\
\text { clinic } \\
\text { assistants }\end{array}$ & 31 & 32 & 41 \\
\hline $\begin{array}{l}\text { Total } \\
\text { participants }\end{array}$ & 60 & 60 & $\begin{array}{l}\text { Total } \\
\text { participants }\end{array}$ & 105 & 112 & 114 \\
\hline
\end{tabular}

Abbreviation: SD, standard deviation. 
on their observations and recollections). Please see the Supplementary Material (available in the online version) for a copy of the care team member interview guides. Interviewees were invited to participate in these brief interviews by research team members who visited each unit across the six hospitals. Any care team member who was available during the hour-long timeframe when the research team was on their unit was able to participate in an interview if they were interested. Care team member interviews lasted from 5 to 20 minutes each with an average duration of 10 minutes. These interviews were audio-recorded, transcribed verbatim, and deidentified.

\section{Data Analysis}

Consistent with rigorous qualitative methods, ${ }^{16}$ transcribed interviews were both inductively and deductively analyzed. Our first step was to develop a preliminary coding dictionary based on questions asked in the interviews. ${ }^{17}$ The subsequent step involved four members of the research team coding four transcripts to refine the coding dictionary and explore the emergence of new codes in the data. The refined dictionary was used by two members of the research team to code all remaining transcripts. Frequent meetings were held throughout the coding process to ensure reliability of coding and agreement about the creation and definitions of new codes as they emerged, consistent with a grounded theory approach. ${ }^{18}$ Saturation of the themes was achieved, as reflected by the consistency of comments from patients and care team members around the key concepts that emerged. This comprehensive and iterative approach to our analysis thus ensures the trustworthiness of our methods with respect to credibility, transferability, dependability, and confirmability of our findings. ${ }^{19}$ We used ATLAS.ti (version 6.0) qualitative data analysis software to support our coding and analysis process.

Considering patients' and care team members' experiences with the inpatient portal, we were interested in perspectives about both use of the portal features and the implications of portal use, as we describe below.

\section{Results}

\section{Use of Portal Features}

Patients and care team members reported patients' use of all portal features; representative quotations describing the use of these features are presented in -Table 1. Across interviews, however, use of three main features was most commonly reportedly: (1) ordering meals; (2) looking up health information; and (3) viewing the care team. The feature of secure messaging was also available, but used less frequently. Below we describe patients' and care team members' perspectives about the use of these four features in greater detail, with additional example quotations from each informant group presented in -Table 3 .

\section{Ordering Meals}

By far, interviewees noted that the most common feature patients used was the "Dining on demand" function that allowed patients to order their meals. As one patient explained, "I liked ordering from the menu and seeing the different options that way." Care team members similarly noted that patients appeared to appreciate this feature. One remarked how, "The most thing they like to do is the 'Dining on demand.' Because they can see pictures and understand."

\section{Looking Up Health Information}

A majority of patients also reported that they had used the portal to look up information while they had been in the hospital and noted that they liked being able to see their vital signs on a regular basis. As one patient told us, "I was able to see my vitals, because sometimes the nurses are kind of in a hurry so they would just hurry up take my vitals and say thank you, even if it was in the middle of the night and I was sleeping or something. So, I could check the next morning and see what my vitals were the night before." Another patient noted how having access to that information at any time was helpful so that one could go back and review the information on their own time: "Definitely because when you're medicated and you're in pain, you don't always remember everything when they're telling you, test results or, you know, what you can do. So, it's helpful to have it to be able to go back and refresh, you know, what you've maybe not heard clearly." Care team members echoed this sentiment. As one reflected, "So, I think that's like good for them to have it right there in front of them, so that they can look at them and know what medications they're taking and stuff like that. So, they can compare like what they're taking at home, what's new, what's old."

\section{Viewing Their Care Team}

A third feature commonly noted as useful was the ability for patients to view the care team while they were in the hospital. Patients reported that they liked being able to see their providers' names and faces, and this helped them to remember who was on their care team. One patient stated, “Well if I wasn't sure of somebody's name or something, it was kind of cool because it had everyone's pictures there so I was able to remember names a lot easier..." Several patients particularly appreciated the ability to see care team members because it helped them recognize their own physicians. As one patient noted, "That was kind of a neat little feature of MyChart that I ran into, the care team there, with names. Sometimes the doctor comes by and introduces himself and the name goes right out of my head because I'm paying attention to other things. So, I could go back and I get that name. And the pictures with it." A care team member similarly explained how a patient appreciated this feature: "And she was 92 and she's showing me, 'Look here's the care team. What's your name? Let me find you on here.' "

\section{Sending Secure Messages}

While the majority of patients interviewed did not indicate they had used the secure messaging function, those patients who did noted that they appreciated the speed with which they could have their problems addressed and/or their questions answered. One patient stated, "Being able to 
Table 3 Patients' and care team members' perspectives about inpatient portal feature use

\begin{tabular}{|c|c|c|}
\hline $\begin{array}{l}\text { Use of portal } \\
\text { features }\end{array}$ & Patients' perspectives & Care team members' perspectives \\
\hline $\begin{array}{l}\text { Dining on } \\
\text { demand }\end{array}$ & $\begin{array}{l}\text { "I find it very convenient to make meal choices using } \\
\text { that...my favorite feature was being able to get on } \\
\text { there and order my meals and...and, you know, not } \\
\text { have to worry about fiddling around with paper } \\
\text { menus and all of that mess." } \\
\text { "To be honest I really liked being able to look at all the } \\
\text { menu stuff." }\end{array}$ & $\begin{array}{l}\text { "As far as like being able to order their meals and stuff, } \\
\text { that seems to be the biggest thing that they...that I've } \\
\text { noticed that patients tend to like. The fact that they can } \\
\text { see that their meal plan, they can order on the tablets. } \\
\text { It...I think it's been pretty positive as far as things go." } \\
\text { "They're definitely getting the 'Dining on demand' if } \\
\text { they're able to have a tablet they're able to do that which } \\
\text { is really good. The PCAs [patient care assistants] don't } \\
\text { have to go in there and do it for them." }\end{array}$ \\
\hline $\begin{array}{l}\text { Looking up } \\
\text { health } \\
\text { information }\end{array}$ & $\begin{array}{l}\text { "I liked the...the MyChart Bedside was better because } \\
\text { I could just log into it and look and see the results } \\
\text { versus having to wait for the doctor or the nurse to } \\
\text { come in and tell me the results." } \\
\text { "I liked the schedule that was on there of what the } \\
\text { various times of when I was going to receive my } \\
\text { medicine and everything. That way I knew what was } \\
\text { coming. I just liked the organization of it." }\end{array}$ & $\begin{array}{l}\text { "The patients can look at their last, their vital signs so } \\
\text { if they have questions-'Hey what's my temperature? } \\
\text { My blood pressure? My pulse?'-they can look at it on } \\
\text { the tablet. They can look at when their meds are due. } \\
\text { So, if you have a patient that's always like, 'I need my } \\
\text { meds at this time', they can look on there and see } \\
\text { what time their medications are due. They can look to } \\
\text { see when their upcoming tests are." } \\
\text { "Why you're here, all your meds, what's coming up later } \\
\text { today, stuff like that. So, l've seen them look at it..." }\end{array}$ \\
\hline $\begin{array}{l}\text { Viewing the } \\
\text { care team }\end{array}$ & $\begin{array}{l}\text { "Well the care team, I would go down and the } \\
\text { doctors, I would look at the doctors on duty today you } \\
\text { know and the nurses on duty... I figured that out you } \\
\text { know which was wonderful. That gives you a name } \\
\text { and a face that way you don't know...you know a } \\
\text { stranger coming into your room. You know some } \\
\text { people are uncomfortable with a stranger coming } \\
\text { into the room which you know, I understand that. You } \\
\text { know, you don't know with people nowadays you } \\
\text { don't know what is going to happen." } \\
\text { “I remembered who was my care team that day, but at } \\
\text { least I could go back and see who was on my care } \\
\text { team, well like if I forgot someone's name, like a PCA's } \\
\text { [patient care assistant's] name, I could look on there } \\
\text { and see exactly who is caring for me for that day... } \\
\text { Especially the doctors, because there may be a couple } \\
\text { different doctors coming in at different days." }\end{array}$ & $\begin{array}{l}\text { "I think they like seeing the pictures of people } \\
\text { because they'll remember, 'Oh yeah that nurse got } \\
\text { me a pop, towel, a blanket,' you know that type of } \\
\text { stuff. So sometimes it is nice when they do have that } \\
\text { feature they can go back and see who their team } \\
\text { was." } \\
\text { "They can see who their doctors are and their nurses. } \\
\text { That is sometimes super confusing to patients } \\
\text { because they have so many people in and out of their } \\
\text { room so knowing, being able to see if they...this is my } \\
\text { medicine doctor, this is my orthopedic doctor, that is } \\
\text { super helpful to them." }\end{array}$ \\
\hline $\begin{array}{l}\text { Secure } \\
\text { messaging }\end{array}$ & $\begin{array}{l}\text { "If you didn't understand something from the doctor } \\
\text { you could message him and ask him." } \\
\text { “My phone wouldn't work when I was in the hospital } \\
\text { for some reason so using the my....using the tablet } \\
\text { was really good. I got to look at my charts and see my } \\
\text { bloodwork and see how things were going, and I also } \\
\text { it let me venture out to check my emails. I messaged } \\
\text { my doctors to see what the...cause like when you look } \\
\text { at your bloodwork it's got this scale and it's got } \\
\text { numbers and I didn't know what they were. So I, it let } \\
\text { me hit a button and ask them questions: 'What does } \\
\text { this mean?' and 'Am I okay? Am I going to live?'” }\end{array}$ & $\begin{array}{l}\text { "We always tell them if it's something you need right } \\
\text { now use your call light and if it's just kind of some- } \\
\text { thing you have a question about a med, not right now, } \\
\text { just kind of want to put it on the radar just use that } \\
\text { and so that way we don't forget instead of writing it } \\
\text { up on their board or something and so that way it } \\
\text { keeps flagging." } \\
\text { "I'm in the room all the time. If they have a question } \\
\text { they can ask me. I don't have time to sit and answer } \\
\text { text messages from patients. It's faster for me to go } \\
\text { into the room and say, 'This is what's going on, I'm } \\
\text { going to update you. Do you have any questions? If } \\
\text { you do write them down.'” }\end{array}$ \\
\hline
\end{tabular}

message my providers when there's a problem or I have a question without having to call in or waiting on a returned call, you know, being able to basically get an answer right away from them." Care team members reported little use of secure messaging and explained this was likely due to how the tablets were provisioned to the patients. As one explained, "I tell the patients that if you do send a message, it should be routine in nature...and then two being you shouldn't be time sensitive. Usually if they put a message in there they might not get a response up to like 24 hours. So routine stuff that is not time sensitive. But certainly, they can ask any question they like." Staff also acknowledged the potential problem of lack of knowledge about the secure messaging feature. As a nurse reflected, "I think it's 
Table 4 Benefits of access to information via the inpatient portal

\begin{tabular}{|c|c|c|}
\hline $\begin{array}{l}\text { Reported } \\
\text { benefits }\end{array}$ & Comments from patients & Comments from care team members \\
\hline $\begin{array}{l}\text { Promotes } \\
\text { independence }\end{array}$ & $\begin{array}{l}\text { "I used it to plan my meals, stuff like that and it's just } \\
\text { very helpful. I liked it. Being informed. Having that } \\
\text { there to basically have-know what's going on without } \\
\text { actually talking to the doctor or anything. It helps a lot." } \\
\text { "Sometimes I had questions and they [care team } \\
\text { members] weren't available. I could always turn to that } \\
\text { [MyChart Bedside] and see, you know, and answer my } \\
\text { own questions." }\end{array}$ & $\begin{array}{l}\text { "I think is helpful you know and again people who know } \\
\text { what their lab work means being able to look at that } \\
\text { and see what their lab work is I think it helps them be } \\
\text { more autonomous." } \\
\text { "I think it makes them feel better because they know } \\
\text { what to expect and they know that they can look it up } \\
\text { whenever they want instead of having to...because we } \\
\text { have some patients who really don't like to be a burden } \\
\text { and they'll tell you that so being able to access that } \\
\text { information on their own really helps them be more at } \\
\text { ease I think." }\end{array}$ \\
\hline $\begin{array}{l}\text { Reduces } \\
\text { anxiety }\end{array}$ & $\begin{array}{l}\text { "So, I think that sometimes you're in the hospital } \\
\text { and you're kind of like 'What did he say? What did } \\
\text { she say?' But with MyChart you can look it up and } \\
\text { then you can even you know more descriptions of } \\
\text { the illness or you know whatever they're looking for } \\
\text { you at the time. It just gets understood better and } \\
\text { you don't have to wonder." } \\
\text { "I liked it so well because my health was quickly } \\
\text { changing and I really didn't understand all of why it } \\
\text { was changing so quickly. And it helped me to } \\
\text { understand those changes." }\end{array}$ & $\begin{array}{l}\text { "So, I think for in her sense, it helped her. She's already } \\
\text { had that anxiety there, just being sick, for being young, } \\
\text { I think it kind of just eased her mind that she could see } \\
\text { it right in front of her." } \\
\text { "They seem to have more, you know, say in the matter } \\
\text { and kind of just probably more comfort knowing } \\
\text { what's coming next." }\end{array}$ \\
\hline $\begin{array}{l}\text { Informs } \\
\text { families }\end{array}$ & $\begin{array}{l}\text { “...if the doctors already noted things and you can } \\
\text { look it up when family members ask when they } \\
\text { come visit." } \\
\text { "So, I had a better idea of when things were coming } \\
\text { so even with family members, I can kind of give them } \\
\text { a heads up on things too. So, that really helped and I } \\
\text { liked that aspect of it." }\end{array}$ & $\begin{array}{l}\text { “I've seen family members like look at their family } \\
\text { members' charts you know like in the room and ask me } \\
\text { questions and then I'll use [the portal] to look at this. } \\
\text { They're asking me a question about this so they're looking } \\
\text { up, I mean it's crazy, they're looking at their tablet asking } \\
\text { me about a mediation or result or and then you know l'm } \\
\text { getting on [the electronic health record] and we're talking } \\
\text { about it. And I mean, I feel like it gives the family members } \\
\text { a little bit more control, a feeling of like okay get some } \\
\text { answers and they can participate more in their family } \\
\text { member's care.” } \\
\text { "...the nurses can direct them there, they can be like, 'Well } \\
\text { you have your tablet let's pull it up so that we can show } \\
\text { your family member,' or whatever...and like I said, it also } \\
\text { opens that line of communication with that patient's } \\
\text { family for them to ask questions in the future.” }\end{array}$ \\
\hline $\begin{array}{l}\text { Empowers } \\
\text { patients }\end{array}$ & $\begin{array}{l}\text { "Well it keeps you more in tune to your health. I } \\
\text { mean it tells you, you got meds coming. It tells you } \\
\text { why you're taking the meds. There's advice that's } \\
\text { good for everybody. 'Cause doctors fail to realize } \\
\text { that we don't understand all that medical termi- } \\
\text { nology. Once they leave I click on that little thing and } \\
\text { it tells you what it's for and it gives you...like I was in } \\
\text { there for osteomyelitis, okay, I click that, I already } \\
\text { knew what it was but I clicked it and, yep, it tells you } \\
\text { what it is and what the symptoms of it are and what } \\
\text { they can do to fix it." } \\
\text { "Oh, it was really nice cause, you know, you could look } \\
\text { up, you know, nutritional facts, stuff like that, you } \\
\text { know...it gave me just kind of a another thing to look } \\
\text { through to kind of improve things on while I was there, } \\
\text { so, you know, that was really nice. Before I really wasn't } \\
\text { probably doing a good job of taking care of myself." }\end{array}$ & $\begin{array}{l}\text { "I just think they feel more empowered, like they are } \\
\text { more a part of their care, their plan of care." } \\
\text { "I think it makes them feel like they have more control } \\
\text { of their care. Everybody likes being in the driver seat } \\
\text { and not the passenger." }\end{array}$ \\
\hline
\end{tabular}


frustrating because family members are messaging their doctor and it's like, 'I messaged this doctor two days ago and nobody got back to me.' The doctors don't really use that; it's just out there."

\section{Benefits of Access to Information via the Inpatient Portal}

Patients' and care team members' comments describing patients' use of MyChart Bedside during their hospitalization indicated that having information available via the portal during their stay was beneficial in four main ways: (1) promoted independence; (2) reduced anxiety; (3) informed families; and (4) increased empowerment. Below, we describe each of these subthemes, and in -Table 4, we provide additional supporting quotes from our interviewed patients and care team members.

\section{Promotes Independence}

Both patients and care team members noted that access to MyChart Bedside while in the hospital was beneficial because it enabled patients to do things more independently. Prior to the availability of portals, patients would have to ask a care team member for test results, for their schedule for the day, or to order meals for them. Offering a portal in the inpatient environment allows the patient to do these actions on their own. For example, one patient explained, "I liked being able to see what my bloodwork was without having to wait on the doctors, see my test results." Another patient reflected, "You know, I'm the kind of person that's always thinking about the next meal, and so for me to be able to, to put that order in myself, to look and order what I want...and not have to wait for somebody to come around and take it..." Care team members also noted this increased independence for patients. As one summarized, "Honestly, I think MyChart Bedside does give a lot of independence for patients, and it gives them something to be a part of their medical care."

\section{Reduces Anxiety}

Patients' use of the inpatient portal during their stay also appeared to have the potential to reduce anxiety for some patients. As one patient explained, "I think that it caused less anxiety because I was able to look at what was going on while I was in the hospital, the tests and the labs and everything they had done, and educate myself on things." Care team members similarly noted this impact. One reflected: "Patients who are anxious about their care a little bit really like to be like, 'Okay, I can see what my vitals were from this morning.' And they can always look up their meds, and they like to know exactly when a med is due."

\section{Informs Families}

Another benefit of inpatient portal use was noted around how access to information in the portal helped keep families informed. As one patient explained, "When my family came in, instead of waiting for a doctor to come in to ask questions, I pretty much had, you know, I had all my medicines there on the tablet. I could just show my parents or whatever, you know, everything that I was taking at the time and pretty much stuff like that." Similarly, care team members reflected how, "It's usually like family members that will come in and maybe the doctors already reviewed things or whatever and then they come in, and then that's a tool for them to go back in and look at results and ask questions and stuff."

\section{Increases Patient Empowerment}

A fourth important benefit of access to information via the patient portal was a noted increase in patients' sense of control and empowerment during their stay. As one patient reflected on the experience of care with the portal, "You could see your lab results and medications and everything. I liked it. I mean it was easy to use and you, if you didn't understand something from the doctor you could message him and ask him. Knowing your medicine, picking out the meals, and knowing how many doctors were studying your problems." One care team member commented how, "I think they feel more informed, like they have more control over what's going on with their care. They can question things. 'Hey, I didn't say that this was okay. I saw that this changed. Why did it change?' " Another care team member summarized, "I think it gives them a sense of control that they need when they have none."

\section{Discussion}

Our study involved an institution-wide deployment of an inpatient portal system at a large AMC exploring the use of the inpatient portal and implications of its use from both patients' and providers' perspectives. The results of our study suggest patients' preferences for using the portal to order meals, look up health information, and view their care team members. Both patients and care team members were positive about the usefulness of these features. Their views on secure messaging, however, were equivocal. Although patients viewed this feature as a means to communicate with their health care providers, care team members generally did not perceive the feature as an effective method to communicate with patients, and there was concern about message response time from doctors given the presence of multiple communication options in the inpatient setting. Our findings support results from prior studies that demonstrated the ability of inpatient portals to generally help improve patients' engagement and experiences. ${ }^{14,20,21}$ Moreover, the results of our study extend the literature due to our focus on a large sample of adult inpatients, as well as our inclusion of the perspectives of care team members about their patients.

Within the context of designing a more personalized health care system, Umar and Mundy proposed a holistic model for understanding how patients can experience a sense of ownership with their health and build stronger relationships with their providers. Their model envisioned technology as a unifier, helping to improve patients': (1) access to the right health information; (2) ability to develop knowledge around this information to make informed decisions; (3) means to foster meaningful partnerships with providers in regard to their health care; and (4) participation 
in activities that enhance their self-efficacy (i.e., accountability, responsibility, and goal management). ${ }^{22}$ We found that the views of the inpatient portal users in our study aligned with Umar and Mundy's model. Patients noted that they appreciated the ability to do things more independently, felt reduced anxiety, liked having their family members informed, and felt more empowered with their health care. Care team members' comments confirmed that they had similarly observed these benefits of portal use by patients and their families.

Given the immense environmental and personal stressors faced by patients in isolated hospital settings, providing them with near real-time access to their health information through a portal appeared to allay many of their concerns and gave them the feeling that they had more control over their health and illness, similar to findings from other studies. ${ }^{14,23}$ Patients in our study appreciated being able to know what was going on with their care as well as the ability to plan during their hospital stay. Similarly, care team members recognized that their patients felt more empowered and knew what to expect with their care, suggesting alignment with Umar and Mundy's model where access to technology fosters a patient's sense of self-efficacy. It has also been shown in other studies that having patients able to manage and be in control of their care with the help of portal information may be associated with increased patient safety. ${ }^{24,25}$

During hospital stays, poor access to personal information, communication barriers, and uncertainty are factors that make patients prone to anxiety. ${ }^{26-30}$ By providing patients access to their health information, inpatient portals may help alleviate some of this anxiety by helping patients and their families better understand both the care they are receiving as well as the experience of hospitalization. ${ }^{31}$ Patients in our study recognized the ability to better educate themselves about their condition and changes to their condition, while not having to wonder about the unknown quite as much. Several care team members empathized with their patients and also noted that the portal seemed to help ease patients' minds by making this information about their condition available on their tablets.

It is possible that, conversely, information sharing through portals could overwhelm patients and create more anxiety. ${ }^{14,32,33}$ Further, the levels at which these factors play a role in the effective use of tablets might be influenced by patient characteristics such as educational attainment and health literacy, ${ }^{6,34}$ and the design of the portal application itself. $^{35}$ While our interviews did not identify such challenges, it is important to conduct more research to identify factors in the inpatient setting that facilitate or inhibit portal use among patients as well as to evaluate the impact of information sharing in this context. In addition, we also acknowledge the possibility of care team members being negatively influenced by patients' use of the portals as portals provide another source of information and means of communication during a patient's inpatient stay. For example, Hefner et al. found that inpatient portal use and associated workflows could be very confusing to care team members, highlighting the need for more training on portal use and integration into patient care processes. ${ }^{36}$ Additional study of care team members' perceptions and experiences can help improve our understanding of these potential challenges with inpatient portal use.

As our findings show, inpatient portals can help not only patients but also their families and caregivers be more engaged in the patient's care. With the patient's consent, family members or caregivers can view laboratory and test results and plans of care, allowing the patient and family to share the same information and, together, to be more engaged. Patients in our study discussed sharing results on the portal with their family members and reported that this helped everyone to be better informed. Notably, access to a portal allows families to communicate with the care team asynchronously, a benefit previously noted to decrease stress of parents of hospitalized children. ${ }^{37}$ Moreover, while they are visiting, family members and caregivers can use the secure messaging feature to send questions to the care team and receive answers upon their next visit, which may then result in less pressure to be present to catch the care team when they are in the patient's room. More engaged, better-informed caregivers may also facilitate better care postdischarge. Such partnerships between patients, caregivers, and their providers demonstrate a means through which a patient could be more involved in their health care, with patients subsequently taking more ownership of their health and building long-term relationships with care providers, imperatives highlighted in the Umar and Mundy model. $^{22}$

Our results interestingly demonstrated a generally unified view of inpatient portals by patients and care team members. Care team members desired an experience for their patients that converged with what patients wanted. This could signify a cultural shift toward the use of patient portals as a potential tool to provide patient-centered care and engage patients. Prior research has highlighted the misalignment between stakeholders as being a critical barrier for the cultural incorporation of inpatient portals, thus a shift in culture could facilitate the adoption, implementation, and use of portals to better empower and engage patients and their families in the care process. ${ }^{31,38}$

This study may be limited in some notable aspects. First, we examined patient and provider perceptions related to portal use in a single health care system. This portal is based on a platform designed by a commercial vendor and features provided across different portal systems may be common. However, some portal features and policies around portal implementation and use might vary across institutions and contribute to variations in user experience. Second, our results may be biased toward inpatient portal use, given that all patient participants had used the inpatient portal. These patients could be more engaged in their care, and their views may vary from those who are less engaged; nonetheless, their views present perspectives that can help inform research and practice. Third, while physicians are clearly vital members of care teams, physicians in this organization were not directly involved with portal provisioning and had 
limited direct interactions with patients that enabled them to learn about patients' experiences with the portal at the time of this study. We do recognize that physicians are also impacted by patient portals and look forward to including their perspectives in future work. Finally, responses were gathered at different points in time and participants' views may be impacted by the time that had elapsed since portal implementation (i.e., recall bias). However, our results indicated a uniformity in views across time that signifies a stability in the findings that, in turn, could be viewed as a strength of our study.

\section{Conclusion}

Inpatient portals are being recognized as an emerging technology that hospitals can use to enhance the delivery of patient-centered care. Our study examined portal use in this context and found important commonalities between patients' and care team members' perspectives. Specifically, many features of the portal were reportedly useful, and both patients and care team members noted that having access to health information through the portal helped patients feel independent, empowered, in control of their health, and less anxious. The shared perspectives of patients and care team members about the benefits of inpatient portal use suggest the importance of this technology in improving patients' experiences while in the hospital, as well as in enhancing the patient centeredness of care.

\section{Clinical Relevance Statement}

Our findings provide early evidence supporting the potential for inpatient portals to improve the patient centeredness of care delivery. Hospital administrators should consider the specific utility of the portal features described in our study to ensure inpatient portals support their organizational and unit needs. Additionally, our study results suggest inpatient portals can help engage key stakeholders such as patients' families and care team members, in addition to the patients they support. Improved understanding of the potential influence and impact of inpatient portals can help hospital administrators and providers in efforts to enhance the health care experience for patients, their families, and their care team members.

\section{Multiple Choice Questions}

1. What inpatient portal feature was used the least frequently?
a. Dining on demand.
b. View care team.
c. Secure messaging.
d. Health information.

Correct Answer: The correct answer is option c, secure messaging. Based on our study, a majority of the patients interviewed did not indicate they had used this feature. Care team members generally did not perceive the feature as an effective method to communicate with patients, and there was concern about message response time from doctors given the presence of multiple communication options in the inpatient setting.

2. What were the main ways in which the study patients found the information available via the inpatient portal to be beneficial?

a. Increased ability to do things independently.

b. Reduced anxiety.

c. Helped keep their families informed.

d. Increased empowerment.

e. All of the above.

Correct Answer: The correct answer is option e, all of the above. Our study found that patients who used the inpatient portal noted they appreciated the ability to do things more independently, felt reduced anxiety, liked having their family members informed, and felt more empowered about their health care. Care team members' comments confirmed that they had similarly observed these benefits of portal use by patients and their families.

\section{Protection of Human and Animal Subjects}

Conduct of this research was reviewed and approved by the Institutional Review Board affiliated with the authors' institution.

\section{Funding}

This research was supported by grants from the Agency for Healthcare Research on Quality [Grant\# R01HS024091, Grant \#R21HS024767, and Grant \#P30HS024379].

\section{Conflict of Interest}

None declared.

\section{Acknowledgments}

The authors wish to thank Dr. Jennifer Hefner, Dr. Timothy Huerta, Lindsey Sova, Danijela Cvijetinovic, Toby Weinert, Allison Silverman, Ayanna Scott, and Karen Alexander, all affiliated with the authors' organization, for their assistance with this project. They are also extremely grateful to the care team members and patients who participated in this study.

\section{References}

1 McAlearney AS, Sieck CJ, Hefner JL, et al. High Touch and High Tech (HT2) proposal: transforming patient engagement throughout the continuum of care by engaging patients with portal technology at the bedside. JMIR Res Protoc 2016;5(04):e221

2 Prochaska JO, Velicer WF. The transtheoretical model of health behavior change. Am J Health Promot 1997;12(01):38-48

3 Rosenstock IM. The health belief model and preventative health behavior. Health Educ Monogr 1974;2(04):354-386

4 Okunrintemi V, Spatz ES, Di Capua P, et al. Patient-provider communication and health outcomes among individuals with atherosclerotic cardiovascular disease in the United States: Medical Expenditure Panel Survey 2010 to 2013. Circ Cardiovasc Qual Outcomes 2017;10(04):e003635

5 Hughes TM, Merath K, Chen Q et al. Association of shared decisionmaking on patient-reported health outcomes and healthcare utilization. Am J Surg 2018;216(01):7-12 
6 Davis K, Schoenbaum SC, Audet AMA. A 2020 vision of patientcentered primary care. J Gen Intern Med 2005;20(10):953-957

7 Aboumatar HJ, Chang BH, Al Danaf J, et al. Promising practices for achieving patient-centered hospital care: a national study of highperforming US hospitals. Med Care 2015;53(09):758-767

8 Irizarry T, DeVito Dabbs A, Curran CR. Patient portals and patient engagement: a state of the science review. J Med Internet Res 2015;17(06):e148

9 Risling T, Martinez J, Young J, Thorp-Froslie N. Evaluating patient empowerment in association with eHealth technology: scoping review. J Med Internet Res 2017;19(09):e329

10 Phelps RG, Taylor J, Simpson K, Samuel J, Turner AN. Patients' continuing use of an online health record: a quantitative evaluation of 14,000 patient years of access data. J Med Internet Res 2014;16 (10): 241

11 Ford EW, Hesse BW, Huerta TR. Personal health record use in the United States: forecasting future adoption levels. J Med Internet Res 2016;18(03):e73

12 Tarver WL, Menser T, Hesse BW, et al. Growth dynamics of patient-provider Internet communication: trend analysis using the Health Information National Trends Survey (2003 to 2013). J Med Internet Res 2018;20(03):e109

13 Prey JE, Woollen J, Wilcox L, et al. Patient engagement in the inpatient setting: a systematic review. J Am Med Inform Assoc 2014;21(04):742-750

14 Woollen J, Prey J, Wilcox L, et al. Patient experiences using an inpatient personal health record. Appl Clin Inform 2016;7(02): 446-460

15 Kelly MM, Coller RJ, Hoonakker PL. Inpatient portals for hospitalized patients and caregivers: a systematic review. J Hosp Med 2018;13(06):405-412

16 Miles MB, Huberman AM. Qualitative Data Analysis: An Expanded Sourcebook. Thousand Oaks, CA: Sage Publications; 1994

17 Crabtree BF, Miller WL. Using codes and code manuals: a template organizing style of interpretation. In: Crabtree BF, Miller WL, eds. Doing Qualitative Research. Vol. 2. Thousand Oaks, CA: Sage; 1999:163-177

18 Glasser BG, Strauss AL. The Discovery of Grounded Theory: Strategies for Qualitative Research. Hawthorne, NY: Aldine de Gruyter; 1967

19 Lincoln YS, Guba EG. Naturalistic Inquiry. Newbury Park, CA: Sage; 1985

20 Greysen SR, Khanna RR, Jacolbia R, Lee HM, Auerbach AD. Tablet computers for hospitalized patients: a pilot study to improve inpatient engagement. J Hosp Med 2014;9(06):396-399

21 Kelly MM, Hoonakker PL, Dean SM. Using an inpatient portal to engage families in pediatric hospital care. J Am Med Inform Assoc 2017;24(01):153-161
22 Umar A, Mundy D. Re-thinking models of patient empowerment. Stud Health Technol Inform 2015;209:175-181

23 Pell JM, Mancuso M, Limon S, Oman K, Lin CT. Patient access to electronic health records during hospitalization. JAMA Intern Med 2015;175(05):856-858

24 Caligtan CA, Carroll DL, Hurley AC, Gersh-Zaremski R, Dykes PC. Bedside information technology to support patient-centered care. Int J Med Inform 2012;81(07):442-451

25 Grossman LV, Choi SW, Collins S, et al. Implementation of acute care patient portals: recommendations on utility and use from six early adopters. J Am Med Inform Assoc 2018;25(04):370-379

26 Gammon J. Analysis of the stressful effects of hospitalisation and source isolation on coping and psychological constructs. Int J Nurs Pract 1998;4(02):84-96

27 Prey JE, Restaino S, Vawdrey DK. Providing Hospital Patients with Access to Their Medical Records. Paper presented at: AMIA Annual Symposium Proceedings; 2014

28 Shuldham CM, Cunningham G, Hiscock M, Luscombe P. Assessment of anxiety in hospital patients. J Adv Nurs 1995;22(01):87-93

29 Teasdale K. Information and anxiety: a critical reappraisal. J Adv Nurs 1993;18(07):1125-1132

30 Walker DM, Menser T, Yen PY, McAlearney AS. Optimizing the user experience: identifying opportunities to improve use of an inpatient portal. Appl Clin Inform 2018;9(01):105-113

31 Collins SA, Rozenblum R, Leung WY, et al. Acute care patient portals: a qualitative study of stakeholder perspectives on current practices. J Am Med Inform Assoc 2017;24(e1):e9-e17

32 Sarkar U, Karter AJ, Liu JY, et al. The literacy divide: health literacy and the use of an internet-based patient portal in an integrated health system-results from the diabetes study of northern California (DISTANCE). J Health Commun 2010;15(Suppl 2):183-196

33 Kelly MM, Dean SM, Carayon P, Wetterneck TB, Hoonakker PL. Healthcare team perceptions of a portal for parents of hospitalized children before and after implementation. Appl Clin Inform 2017;8(01):265-278

34 Coughlin SS, Stewart JL, Young L, Heboyan V, De Leo G. Health literacy and patient web portals. Int J Med Inform 2018;113:43-48

35 Yen PY, Walker DM, Smith JMG, Zhou MP, Menser TL, McAlearney AS. Usability evaluation of a commercial inpatient portal. Int J Med Inform 2018;110:10-18

36 Hefner JL, Sieck CJ, McAlearney AS. Training to optimize collaborative use of an inpatient portal. Appl Clin Inform 2018;9(03):558-564

37 Kelley T, Docherty S, Brandon D. Information needed to support knowing the patient. ANS Adv Nurs Sci 2013;36(04):351-363

38 Alpert JM, Morris BB, Thomson MD, Matin K, Brown RF. Implications of patient portal transparency in oncology: qualitative interview study on the experiences of patients, oncologists, and medical informaticists. JMIR Cancer 2018;4(01):e5 